\title{
Hydrographic situation during cruise M84/3 and P414 (spring 2011) in the Mediterranean Sea
}

\author{
D. Hainbucher ${ }^{1}$, A. Rubino ${ }^{2}$, V. Cardin ${ }^{3}$, T. Tanhua ${ }^{4}$, K. Schroeder ${ }^{5}$, and M. Bensi ${ }^{3}$ \\ ${ }^{1}$ CEN, Institut für Meereskunde, University of Hamburg, Bundesstraße 53, 20146 Hamburg, Germany \\ ${ }^{2}$ Università Ca’ Foscari di Venezia, Dorsoduro, 2137 - C.A.P. 30121, Italy \\ ${ }^{3}$ OGS - Istituto Nazionale di Oceanografia e di Geofisica Sperimentale, Borgo Grotta Gigante, 42/c, 34018 Sgonico, \\ Trieste, Italy \\ ${ }^{4}$ GEOMAR Helmholtz Centre for Ocean Research Kiel, Department of Chemical Oceanography, Düsternbrooker Weg 20, \\ 24105 Kiel, Germany \\ ${ }^{5}$ Istituto di Scienze Marine - ISMAR, Consiglio Nazionale delle Ricerche (CNR), Arsenale - Tesa 104, Castello 2737/F, \\ 30122 Venice, Italy
}

Correspondence to: D. Hainbucher (dagmar.hainbucher@zmaw.de)

Received: 16 October 2013 - Published in Ocean Sci. Discuss.: 16 December 2013

Revised: 16 June 2014 - Accepted: 18 June 2014 - Published: 29 July 2014

\begin{abstract}
Aspects of hydrography and large-scale circulation observed in the Mediterranean Sea during the M84/3 and P414 cruises (April and June 2011, respectively) are presented. In contrast to most of the recent expeditions, which were limited to special areas of the basin, these two cruises, especially the M84/3, offered the opportunity of delineating a quasi-synoptic picture of the distribution of the relevant physical parameters along a section extending through the whole Mediterranean, from the Lebanese coast up to the Strait of Gibraltar. The foci of our analysis are the observed water mass properties and velocity fields. The first are investigated through $T-S$ diagrams and an optimum multiparameter (OMP) analysis and the results are discussed also in the context of recently identified modes of variability; the second are studied by comparing the velocity fields observed using a vessel-mounted Acoustic Doppler Current Profiler and those calculated from the observed density fields. Overall, a distribution of temperature, salinity and geostrophic velocities emerges, which is far from that observed before the beginning of the so-called "Eastern Mediterranean Transient", a major climatic shift in the hydrography and circulation of the Mediterranean Sea which began at the end of the 1980s. The picture which emerges helps to further address the complexity of long-term evolution of hydrography and large-scale circulation of the Mediterranean Sea.
\end{abstract}

\section{Introduction}

The Euro-African Mediterranean Sea is a marginal sea, as it is separated from the Atlantic Ocean through the narrow Strait of Gibraltar. It consists of two sub-basins, the western (WMed) and the eastern (EMed) Mediterranean, which communicate through the broad $(145 \mathrm{~km})$ and shallow (maximum depth at its western sill is $550 \mathrm{~m}$ ) Sicily Channel. This represents a natural barrier for the inter-basin circulation of intermediate and deep waters. As a consequence of the different bathymetry and the different forcings which exist between the two sub-basins, the WMed and EMed show distinct differences both in their hydrographic conditions and circulation. Different attempts, based on observational evidence, to schematize surface as well as intermediate and deep paths of circulation of the Mediterranean Sea have been made in the past (see e.g. the POEM Group, 1992; Malanotte-Rizzoli et al., 1997, 1999; Robinson et al., 2001; Roether et al., 2007; Schroeder et al., 2012).

The surface layer in the WMed is dominated by the inflow of relatively low-salinity Atlantic Water (AW) through the Strait of Gibraltar. This water mass is subject to different, mostly wind-driven currents that coexist with a complex, mostly cyclonic path of circulation. The AW flows from the WMed along the Algerian coast and bifurcates at the Sicily Strait. One branch, accounting for about $1 / 3$ of the total water transport, deviates eastwards, entering the Tyrrhenian Sea 
whereas the other branch, accounting for about $2 / 3$ of the transport, enters the eastern basin (Pierini and Rubino, 2001; Molcard et al., 2002). The intermediate layer is occupied by the Levantine Intermediate Water (LIW), originated in the EMed, whose core is found typically between 200 and $400 \mathrm{~m}$ depth. The abyssal water mass in the WMed, produced by shelf and open-ocean convection, is the Western Mediterranean Deep Water (WMDW), which is formed in the Gulf of Lion (see e.g. Leaman and Schott, 1991).

In the EMed, the AW, the Levantine Surface Water (LSW) and the Ionian Surface Water (ISW) dominate in near-surface layers, approximately down to $100 \mathrm{~m}$ depth. In the intermediate layer the LIW is clearly associated with a salinity maximum which is found typically between 50 and $600 \mathrm{~m}$ depth; in the eastern Mediterranean in this depth horizon Cretan Intermediate Water (CIW) can also be found. Note that the depth variability of such salinity maximum is largely regional: generally, it increases westward. LIW exerts a large influence on the oceanography and climatology of the Mediterranean Sea: formed in the Levantine Sea and in the Rhodes Gyre (Özturgut, 1976), it is able to flow through the Sicily Channel into the WMed and thus represents the intermediate water mass connection between the two basins. Additionally, more regionally confined water masses, like the Cretan Intermediate Water (CIW) can be found in the intermediate layer of the EMed (Robinson et al., 2001). The Adriatic Deep Water (AdDW) and water of Aegean origin named Cretan Deep Water (CDW) (Schlitzer et al., 1991) are deep water masses and are produced in the two deep water formation regions of the EMed. Thus, the predominant water mass of the bottom layers filling the abyssal plains of the Ionian and Levantine basins is the Eastern Mediterranean Deep Water (EMDW), being a mixture of AdDW, CDW and shallower water masses.

The EMed has gone through dramatic changes in hydrography and circulation during the last decades. The most drastic of those changes is known as the Eastern Mediterranean Transient (EMT; see Roether et al., 1996). Together with the occurrence of anomalous meteorological, oceanic, and hydrological phenomena, the source of the EMDW shifted abruptly from the Adriatic Sea to the Aegean Sea (see e.g. Roether et al., 1996; Klein et al., 1999; Lascaratos et al., 1999). As a consequence, the characteristics of the EMDW changed dramatically and resulted in a new, rapidly and still evolving thermohaline circulation. The deep parts of the Ionian basin were filled by the dense waters of Aegean origin and the isopycnals were lifted up by several hundred metres (Klein et al., 1999). Additionally, the northern Ionian upper circulation changed from anticyclonic to cyclonic in 1997, whereupon Borzelli et al. (2009) suggested that this phenomenon was associated with the filling up of the Ionian bottom layer with Cretan Sea Overflow Water (CSOW) following the EMT. Gačic et al. (2010) generalized this assumption and suggested that the redistribution of Ionian water masses, resulting from changes in the thermohaline properties of waters entering the basin, can sustain inversions of the upperlayer circulation. They propose a feedback mechanism between variations in the properties of waters from the southern Adriatic Sea and the Ionian circulation which they name BiOS (Adriatic-Ionian Bimodal Oscillating System).

Concerning the basin's long-term stability in the WMed, one has to note that, since 1960, the basin has experienced a marked long-term warming and salinification trend in its deep water (Béthoux et al., 1990). Possibly, such a trend has started well earlier, but the accuracy of the available observations does not allow a statistically significant reconstruction. These variations have been mostly attributed to changes in regional climate. Furthermore, two conditions led to an event which is known as the Western Mediterranean Transition (WMT): a significant increase both in temperature and salinity in the intermediate and deep layers occurred in recent years, which was identified as a propagating signal from the eastern basin to the western one originating from the EMT (Schroeder et al., 2006). The winters of 2004/2005 and 2005/2006 were extreme with a high rate of heat loss, less precipitation and persistent winds. This led to strong deep convection increasing also temperature and salinity in the WMed's deep layers up to a depth of about $1600 \mathrm{~m}$ (LopezJurado et al., 2005; Schroeder et al., 2008). These changes became noticeable by an uplift of the isopycnals and by sharp inversions in the temperature-salinity diagrams.

In this study we present aspects of hydrography and largescale circulation observed in the Mediterranean Sea during cruises M84/3 and P414 (April and June 2011, respectively) on a section extending from the eastern parts of the Mediterranean to the Strait of Gibraltar in the west. Special attention is paid to identify differences between the eastern and western basins, whilst elsewhere in this special issue (Cardin et al., 2014), aspects of the long-term variability in hydrography and circulation are presented which complement this investigation, particularly as far as the evolution of the thermohaline properties of the EMed during the last three decades is concerned. Similarly, in a study using transient tracers, Schneider et al. (2014), report on changes in ventilation of the Mediterranean Sea. Our focus here is a discussion of the observed water mass properties analysed through $T-S$ diagrams and through an optimum multiparameter (OMP) analysis and a comparison between observed acoustic Doppler current profiler (ADCP) velocities and computed geostrophic velocities. Quasi-synoptic data like the ones presented here are rare and hence very valuable, although they refer to just one single section and cannot be used to elucidate threedimensional structures of circulation and hydrography. The distributions of salinity, temperature and density along the section occupied by the M84/3 cruise have been reported by Tanhua et al. (2013b). 


\section{Data and methods}

Since the EMT started at the end of the 1980s several surveys have been carried out in the Mediterranean to monitor the evolution of the basin's hydrography, circulation and biogeochemistry (POEM, 1987; POEM-BC, 1991; LIWEX, 1995; BOUM, 2008). However, most of them were restricted to special areas. METEOR cruise M84/3 constitutes an exception, as it is one of very few recent cruises (another one was the BOUM cruise, see Moutin et al., 2012), carried out after the appearance of the EMT, which ran on a section across the whole Mediterranean Sea with the goal of producing a quasi-synoptic view of the distribution of relevant physical and chemical properties in both basins. Furthermore, it reoccupied relevant stations of previous surveys, most importantly several of the stations from the METEOR survey M5/6 in 1987, which provided the last view of the situation before the EMT. POSEIDON cruise P414 (2011) was designed to complete M84/3, with stations located especially in the southern Adriatic and northern Ionian Sea. One major goal of that cruise was to observe the overflow of dense water of Adriatic origin in the Ionian basin, with the purpose of monitoring the effects of the thermohaline changes observed in the Adriatic on the EMDW (Bensi et al., 2013a). Both cruises were designed to follow the lines of the GO-SHIP Program (Global Ocean Ship Based Hydrographic Investigation Program, www.go-ship.org), which aims at creating a globally coordinated network of sustained hydrographic sections as part of the global ocean/climate observing system. Besides acquiring data for a nearly synoptic picture of the water mass property distribution across the whole Mediterranean Sea, the data collected by these two cruises can be used to determine changes in the circulation and in the distribution of properties and thereby fill in the gaps in the knowledge of the Mediterranean system.

More information about the cruises can be found in Tanhua et al. (2013a) and Hainbucher (2012).

\subsection{Conductivity-temperature-depth (CTD)/rosette and hydrographic samples}

Altogether, 61 full depth standard hydrographic stations were sampled during cruise M84/3 (Fig. 1a) and 33 full depth standard hydrographic stations during cruise P414 (Fig. 1b). A SeaBird SBE911plus CTD-O2 probe equipped with dual sensors of temperature, salinity and oxygen was employed attached to a SeaBird carousel 24 (12) bottle water sampler during the M84/3 (P414) together with an altimeter. Additionally, a fluorometer sensor was installed on the CTD during the M84/3 cruise and a digital reversing thermometer was attached to the probe for calibration purposes on both cruises.

At almost all stations water samples for dissolved oxygen (DO) were taken at different depths throughout the whole water column. Dissolved oxygen from bottle samples were analysed on board using a Winkler potentiometric method.

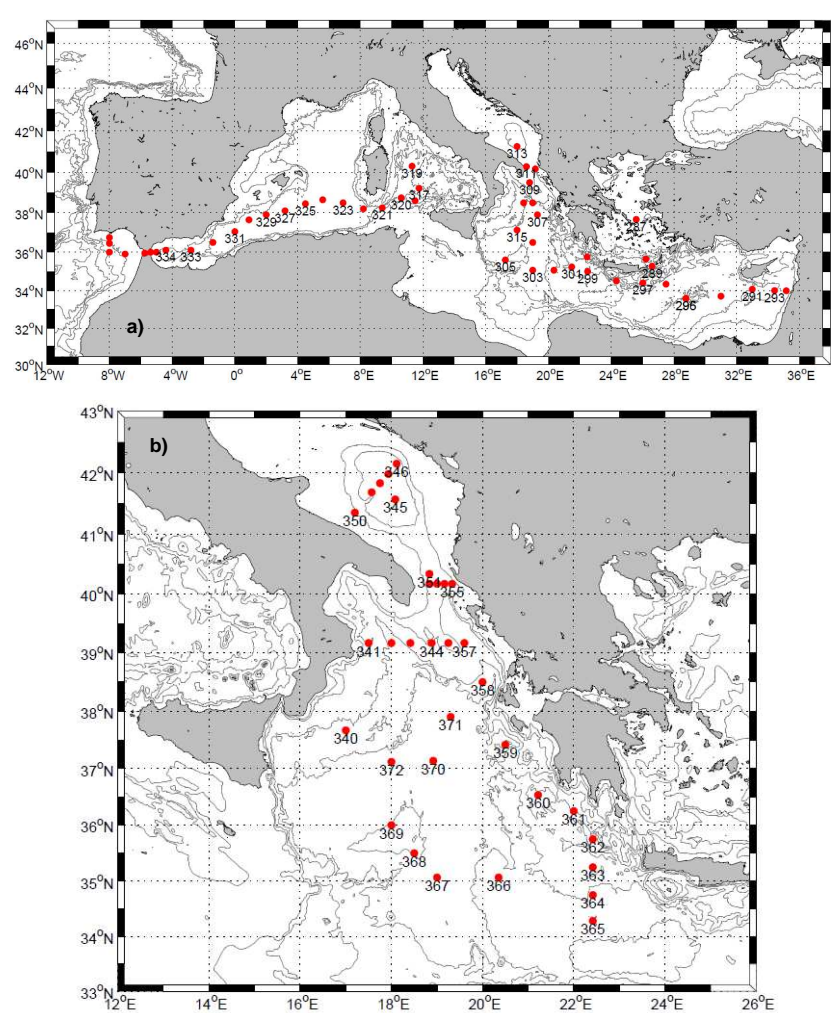

Figure 1. (a) CTD stations (red dots) of METEOR cruise M84-3 during April 2011. Depth contour lines are 200, 500, 1000, 2000, 3000,3500 and $4000 \mathrm{~m}$. (b) CTD stations (red dots) of POSEIDON cruise P414 during June 2011. Depth contour lines are 200, 500, $1000,2000,3000,3500$ and $4000 \mathrm{~m}$

A detailed description of oxygen sampling and distribution during cruise M84/3 can be found in Tanhua et al. (2013a, b). Dissolved oxygen is relevant in the discussion here only in the context of the applied OMP analysis.

From three depth levels, depending on the vertical profile of the stations, water samples were taken also for salinity analysis for calibration purposes and they were analysed onboard using a Guildline Autosal Salinometer.

Temperature, salinity and pressure data were postprocessed by applying Seabird software and MATLAB routines. Spikes were removed, 1 dbar averages calculated, and temperature, salinity, and dissolved oxygen corrected with a regression analysis which fits the downcast profiles with the temperature, salinity and DO. Since the corrections applied to these parameters were small, the data quality can be considered excellent. Overall accuracies are within expected ranges: $0.002{ }^{\circ} \mathrm{C}$ for temperature, 0.003 for salinity and $2 \%$ of saturation for dissolved oxygen. Additionally, we calculated potential temperature with the appropriate MATLAB routines. (We always refer to potential temperature when we use the term temperature in our discussions and figures.) 


\subsection{Acoustic Doppler current profiler (ADCP) velocity measurements}

A vessel mounted ADCP (Teledyne RD Instruments) $38 \mathrm{kHz}$ (with bin size of $32 \mathrm{~m}$ ) was used during the M84-3 cruise. On P414 cruise we used an ADCP (Teledyne RD Instruments) $75 \mathrm{kHz}$ ADCP (with bin size of $8 \mathrm{~m}$ ). Both worked in narrowband mode. The data were post-processed with the software package ossi14 (ocean surveyor sputum interpreter), developed by the Leibniz Institute of Marine Sciences, Kiel, which also corrects for the misalignment angle. An objective quality control of the data was not performed as no data for comparison or correction (like additional IADCP data) were available.

\subsection{Quantification of water mass fractions}

The mixing of water masses and their spatial distributions in the western and eastern Mediterranean Sea were determined using the OMP analysis developed by Tomczak (1981) and described in detail in Tomczak and Large (1989). To apply this method we assume that all hydrographic parameters are conserved and therefore not influenced by biogeochemical processes. We apply this assumption also for dissolved oxygen as our analysis is conducted over a limited region. However, we have to keep in mind that consumption along the pathways can play a role due to the rather long turnover times in the Mediterranean Sea which in the deep waters may amount to decades. Another problem is that the OMP method assumes steady-state situations while the period under consideration is characterized by a transient process (EMT, WMT). With these restrictions, although we believe they can add valuable information to our analyses, our OMP results have to be considered as tentative.

The OMP method is essentially based on establishing a linear system of $n$ equations from observations of $n-1$ parameters and from the equation of mass conservation, and by deriving the contribution of the $n$ water types to a given water sample as the exact solution to the $n$ equations. For our analyses the method bears two challenges: the determination of parameter weights and the determination of water types. As described in Cardin et al. (2011) and in Kovačević et al. (2012), who applied the method to the Adriatic Sea and to the Ionian Sea, respectively, the weight for each parameter was derived as follows: the variance of each parameter of the considered water masses was calculated within the relevant vertical water layer and for the relevant stations. The largest variance of the same parameter among the considered water masses is represented by $\mathrm{v} 2$. The variance (v1) of the overall mean (the average of the considered different mean values associated with the different water masses) is determined. The ratio between $v 1$ and $v 2$ represents the weight, i.e. the relevance of each parameter used in the calculation. Some additional adjustments are made to equate salinity and mass conservation weights to that of temperature after normalization
Table 1. Water masses and their characteristics for (a) the WMed and (b) the EMed. Acronyms used to define water masses: AW (Modified Atlantic Water), LSW (Levantine Surface Water), LIW (Levantine Intermediate Water), WMDWn (Western Mediterranean Deep Water new), WMDWo (Western Mediterranean Deep Water old), AdDW (Adriatic Deep Water), CDW (Cretan Deep Water).

\begin{tabular}{lrrr}
\hline \multicolumn{4}{l}{ (a) Western Mediterranean Sea } \\
Water Mass & Temperature $\left({ }^{\circ} \mathrm{C}\right)$ & Salinity & Oxygen $\left(\mu \mathrm{mol} \mathrm{kg}^{-1}\right)$ \\
\hline AW & 16.39 & 36.381 & 230 \\
LIW & 14.01 & 38.726 & 164 \\
WMDWn & 12.905 & 38.485 & 185 \\
WMDWo & 12.870 & 38.462 & 179 \\
\hline (b) Eastern Mediterranean Sea & & \\
\hline Water Mass & Temperature $\left({ }^{\circ} \mathrm{C}\right)$ & Salinity & Oxygen $\left(\mu \mathrm{mol} \mathrm{kg}^{-1}\right)$ \\
\hline AW & 15.20 & 38.562 & 214 \\
LSW & 16.85 & 39.217 & 216 \\
LIW & 16.33 & 39.180 & 213 \\
AdDW & 13.25 & 38.730 & 197 \\
CDW & 14.43 & 39.040 & 197 \\
\hline
\end{tabular}

(to sum of 100) of the values. The weights reflect the degree of conservativeness of each parameter, measurement accuracy and other processes which may render some parameters less reliable than others (Tomczak and Large, 1989). Therefore, temperature and salinity (and mass conservation) always obtain the largest weights. For our OMP analysis we additionally added dissolved oxygen, as this parameter possesses the same vertical resolution (1 $\mathrm{m}$ after averaging) as temperature and salinity due to the fact that it was measured through CTD sensors. Note that, because high weights are obtained for temperature and salinity, other parameters unavoidably exert a smaller influence on the OMP results. The results for weights came up as follows: temperature, salinity and conservation of mass equals 33 and oxygen equals 1 . In fact, the effect of dissolved oxygen is negligibly small reflecting thereby the delicate assumption that in our case we regard dissolved oxygen to be a conservative property.

In the Mediterranean Sea the water mass definitions are broadly diversified and the definition of their characteristics differs often to some extent, presumably due to location and time when the water mass was found. Ideally, properties of water types are defined in the source region and reasonably back in time, which certainly is not possible for most hydrographical investigations due to lack of data. Therefore, in our study water mass properties were determined with the help of $T-S$ diagrams, profiles and the knowledge about typical water mass distributions in the Mediterranean Sea. The characteristics are listed in Table 1. Depending on season and location, as already stated, the properties of the water masses can vary distinctly. Table 2 specifies temperature and salinity values found in the literature for the relevant water masses (Roether et al., 1998; Millot, 1999; Lascaratos et al., 1999; Theocharis et al., 1999; Gertman et al., 2006; Schroeder et 

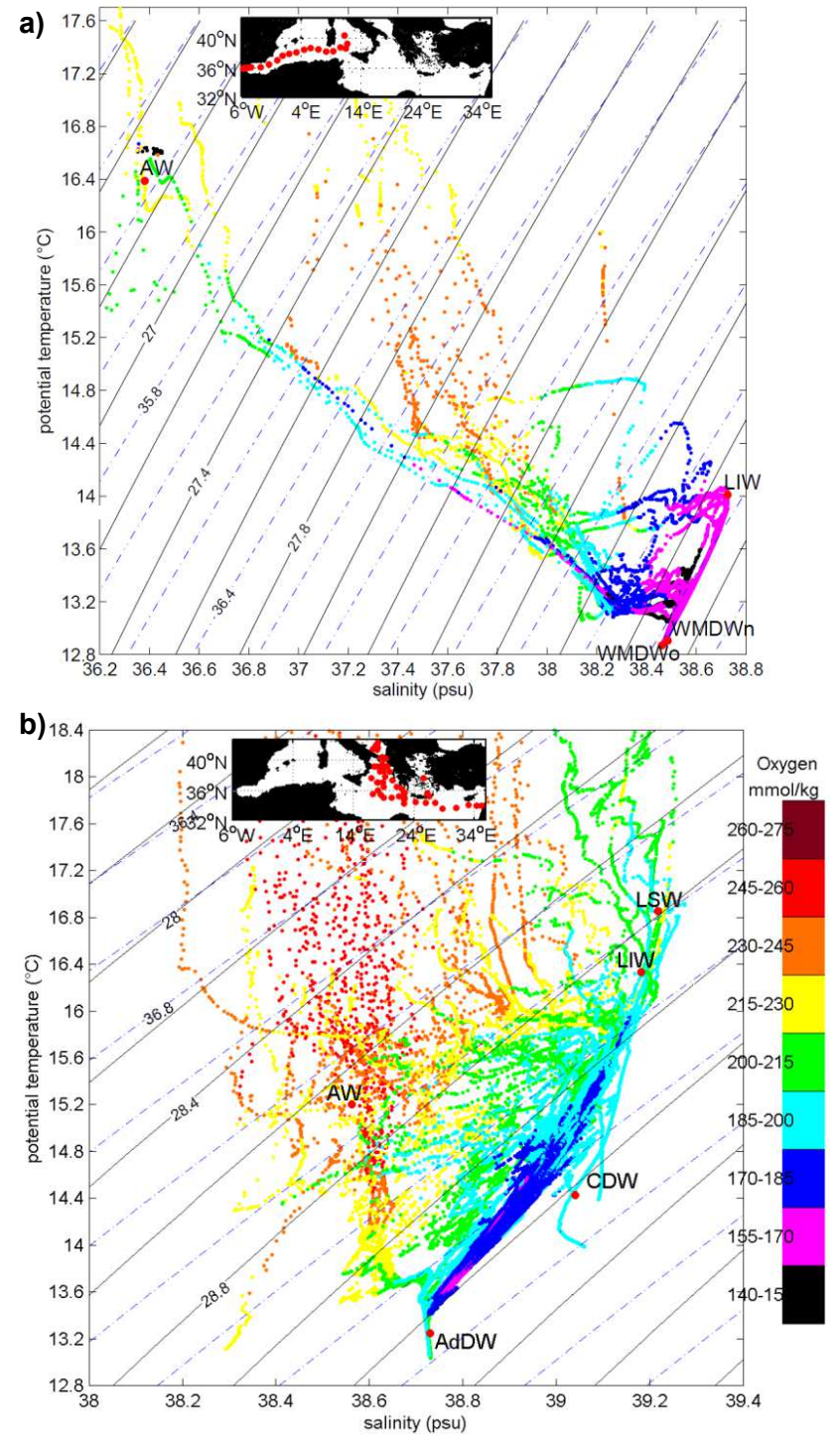

Figure 2a. $T-S$ diagrams of the western (a) and eastern (b) Mediterranean Sea. Colours represent the concentration of oxygen in $\mu \mathrm{mol} \mathrm{kg}{ }^{-1}$. All depth levels from $0 \mathrm{~m}$ to bottom are taken into account. The locations of water mass sources are indicated by red dots (AW = Modified Atlantic Water, LSW = Levantine Surface Water, LIW $=$ Levantine Intermediate Water, WMDW $=$ Western Mediterranean Deep Water, AdDW = Adriatic Deep Water, ADW $=$ Cretan Deep Water). The inset panels show the location of considered stations. Note that the scales of $T$ and $S$ of the two panels are not identical. Data are from cruise M84-3 and P414 in spring 2011.

al., 2006; Kovačević et al., 2012; Bensi et al., 2013a, b). Note that the values presented in Table 1 refer to the year 2011, and might not be valid for other years. For instance, for a water mass analysis of years prior to the EMT the values of temperature and salinity in Table 1 are too high. Again here, the possible weakness of our OMP analysis, i.e. the fact that we are not in the presence of a steady-state situation, is evident.

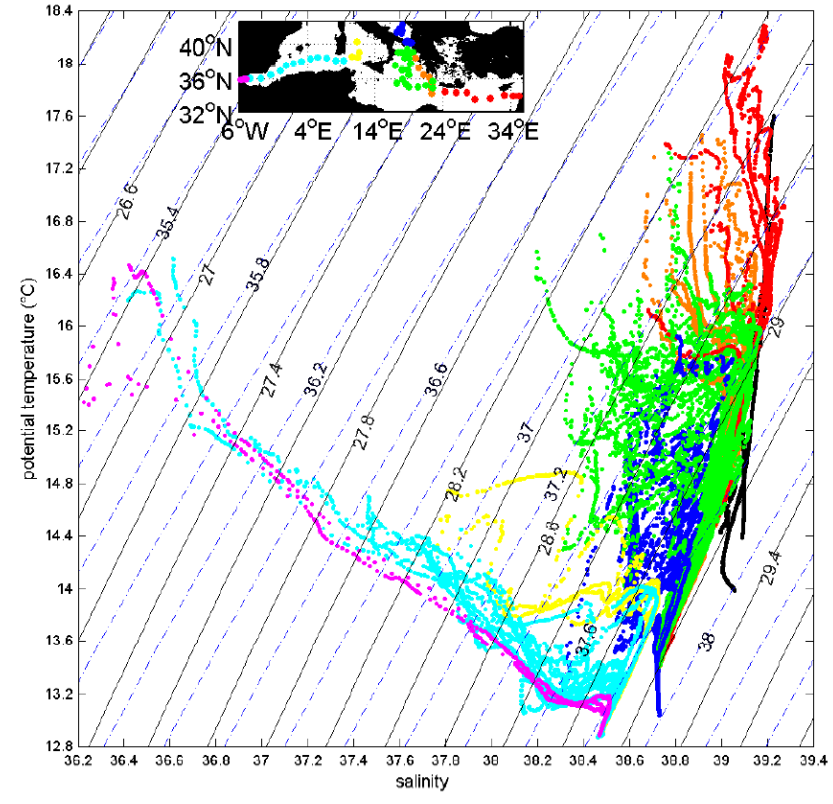

Figure 2b. $T-S$ diagram of all CTD stations taken during cruise M84-3 and P414 in spring 2011. Values from $50 \mathrm{~m}$ depth down to the bottom are considered. Colours show different regions of the Mediterranean Sea. Black dots: Aegean Sea, red dots: Levantine Sea, green dots: Ionian Sea, orange dots: Hellenic Trench, blue dots: Adriatic Sea, yellow dots: Tyrrhenian Sea, cyan dots: remaining western Mediterranean Sea, magenta dots: Strait of Gibraltar. Isolines for potential density $\sigma_{0}=\rho_{0}$ (referenced to sea surface) $-1000 \mathrm{~kg} \mathrm{~m}^{-3}$ (black continuous line) and for potential density $\sigma_{2}=\rho_{2000}$ (referenced to $2000 \mathrm{~m}$ ) $-1000 \mathrm{~kg} \mathrm{~m}^{-3}$ (blue dashed line) are given. Inset panel shows the location of the different stations.

In the WMed we generally find four major water masses (Fig. 2a, panel a): Modified Atlantic Water (AW) in the surface layer, LIW in the intermediate layer, and old and new WMDW from mid-depths down to the bottom. Our definition for AW in the WMed results from the $T-S$ profiles of station 334 , which is close to the entrance of the Strait of Gibraltar, where we find a pronounced salinity minimum in the surface layer. The definition of LIW for the WMed is given by the $T-S$ profiles of station 320, which is close to the Channel of Sicily, where we find the salinity maximum at about $350 \mathrm{~m}$ depth. As is known, WMDW is a mixture of water masses resulting from deep convection in the Gulf of Lion. Old and new WMDW were determined by considering the values encountered in the hook-like $T-S$ structures of Fig. $6 \mathrm{~b}$ and c: new WMDW is slightly warmer and saltier than older WMDW, and more oxygenated. Thus, for the OMP analysis we focus on these four main water masses.

For the EMed we also revert to the basic source water masses: AW, LSW for the surface layers, LIW for the intermediate layers and AdDW and CDW for the bottom layers (Fig. 2a, panel b). Note again that here we choose the characteristics of the year 2011 for our analysis but the pre-EMT 
Table 2. Water masses and their characteristics as found in the literature for (a) the WMed and (b) the EMed (Roether et al., 1998; Millot, 1999; Lascaratos et al., 1999; Teocharis et al., 1999; Gertman et al., 2006; Schroeder et al., 2006; Kovačević et al., 2012; Bensi et al., 2013a, b). Ranges of properties are given if possible. Acronyms used to define water masses: AW (Modified Atlantic Water), LSW (Levantine Surface Water), LIW (Levantine Intermediate Water), WMDWn (Western Mediterranean Deep Water new), WMDWo (Western Mediterranean Deep Water old), AdDW (Adriatic Deep Water), CDW (Cretan Deep Water).

\begin{tabular}{lll}
\hline \multicolumn{3}{l}{ (a) Western Mediterranean Sea } \\
\hline Water Mass & Temperature $\left({ }^{\circ} \mathrm{C}\right)$ & Salinity \\
\hline AW & $>14$ & $>36.5$ \\
LIW & $>13.1$ & $>38.47$ \\
WMDWn & 12.9 & 38.48 \\
WMDWo & $12.75-12.80$ & $38.44-38.46$ \\
\hline
\end{tabular}

(b) Eastern Mediterranean Sea

\begin{tabular}{lll}
\hline Water Mass & Temperature $\left({ }^{\circ} \mathrm{C}\right)$ & Salinity \\
\hline AW & $17.7-23.29$ & $37.38-38.10$ \\
LSW & $17.0-28.0$ & $39.0-39.4$ \\
LIW & $12.85-14.2$ & $38.37-38.80$ \\
AdDW & $13.00-13.60$ & $38.663-38.72$ \\
CDW & $13.66-14.2$ & $38.80-38.95$ \\
\hline
\end{tabular}

salinity for AdDW was distinctly lower. Much of the old AdDW is still present in the EMed and therefore our choice might underestimate the CDW.

AW was defined according to the profiles of stations $304 / 305$ where we found the salinity minimum at around $100 \mathrm{~m}$ depth. The locations of these stations were closest to the Sicily Channel where AW enters the EMed. For LSW we considered the $T-S$ characteristics at the surface of station 287, which is located in the Aegean Sea. Note that LSW is usually predominant during summer with much higher temperature values than those found during these cruises at the beginning of the summer season. LIW was defined according to station 296 located in the centre of the Levantine basin, where we found the salinity maximum at $\sim 170 \mathrm{~m}$ depth. We assume that the EMDW, which we also found during our cruises, results from the mixing of AdDW and CDW and therefore it is not taken into account for the OMP analyses. AdDW is defined according to the profiles collected in the Strait of Otranto and CDW according to the profiles collected in the Kasos Strait.

\subsection{Geostrophic velocities}

Using pressure, temperature and salinity data, geostrophic velocities have been calculated for cross sections through the western and eastern Mediterranean Sea. The reference layer of no motion was set to $1000 \mathrm{~m}$. The use of deeper layers of no motion did not change the results substantially. Note that, in general, the distance between stations was too large to resolve any mesoscale features in the velocity distributions. These are mostly limited by the Rossby radius of deformation, which is of the order of $10-15 \mathrm{~km}$ in the Mediterranean Sea (Robinson et al., 2001).

\section{Analysis and discussion}

The general state of the circulation in the Mediterranean Sea for spring 2011 is shown exemplarily by the map of the Absolute Dynamic Topography (ADT) averaged for April 2011 (Fig. 2c). A variety of sub-basin-scale gyres can be identified for the eastern as well for the western Mediterranean Sea. A complete discussion of these features for the EMed can be found elsewhere in this issue (Cardin et al., 2014). The ADT shows a host of very complex, highly spatially variable circulation features in the basin. Such a complexity can be only partially captured by our in situ measurements.

\subsection{Water mass properties and vertical distribution}

To define the water mass properties observed during the M84/3 and P414 cruises, potential temperature/salinity diagrams $(T-S)$ constructed for different layer depths and regions are considered. Figure $2 \mathrm{~b}$ gives an overview of the $T-S$ characteristics in the whole Mediterranean Sea measured in April and June 2011, which can be considered as representative for the spring season. It highlights major differences existing between the EMed and WMed stratification. If we exclude a surface layer extending down to around $50 \mathrm{~m}$, overall, in the EMed, values vary in a relatively small salinity range (between 38.4 and 39.1, i.e. $\Delta S=0.7$ ) and in a relatively large temperature range (between $13.0^{\circ} \mathrm{C}$ and $18.2^{\circ} \mathrm{C}$, i.e. $\Delta T=5.2^{\circ} \mathrm{C}$ ). In contrast, in the WMed the values vary in a much broader salinity range (from about 36.4 to 38.7 , i.e. $\Delta S=2.3$ ), but in a relatively narrow temperature range (from about 12.9 to $15.9^{\circ} \mathrm{C}$, i.e. $\Delta T=3.0^{\circ} \mathrm{C}$ ). Differences between the two sub-basins are encountered also in the water properties close to the bottom: in particular, the abyssal layer of the EMed is warmer and saltier than that of the WMed. In the former, salinity and temperature values range between $13.40-13.64^{\circ} \mathrm{C}$ and $38.72-38.79$, while in the latter they range between $12.87-13.29^{\circ} \mathrm{C}$ and $38.46-38.58$. As a consequence, bottom density reaches values $\sigma_{0} \sim 29.30 \mathrm{~kg} \mathrm{~m}^{-3}$ $\left(\sigma_{2} \sim 37.81 \mathrm{~kg} \mathrm{~m}^{-3}\right)$ in the EMed and $\sigma_{0} \sim 29.10 \mathrm{~kg} \mathrm{~m}^{-3}$ $\left(\sigma_{2} \sim 37.75 \mathrm{~kg} \mathrm{~m}^{-3}\right)$ in the WMed.

As expected, the LIW signal is stronger in the EMed than in the WMed (Fig. 3). Indeed, the LIW spreads westwards from its formation sites (in the northeastern Levantine Sea and Rhodes cyclonic gyre; see e.g. Ovchinnnikov, 1984; Malanotte-Rizzoli and Hecht, 1988; Lascaratos, 1993) and it is identified by a relative salinity maximum encountered at $\sim 50-100 \mathrm{~m}$ in the Levantine Sea or $\sim 200-600 \mathrm{~m}$ in the Ionian Sea and WMed, whereas in the lower depth also 


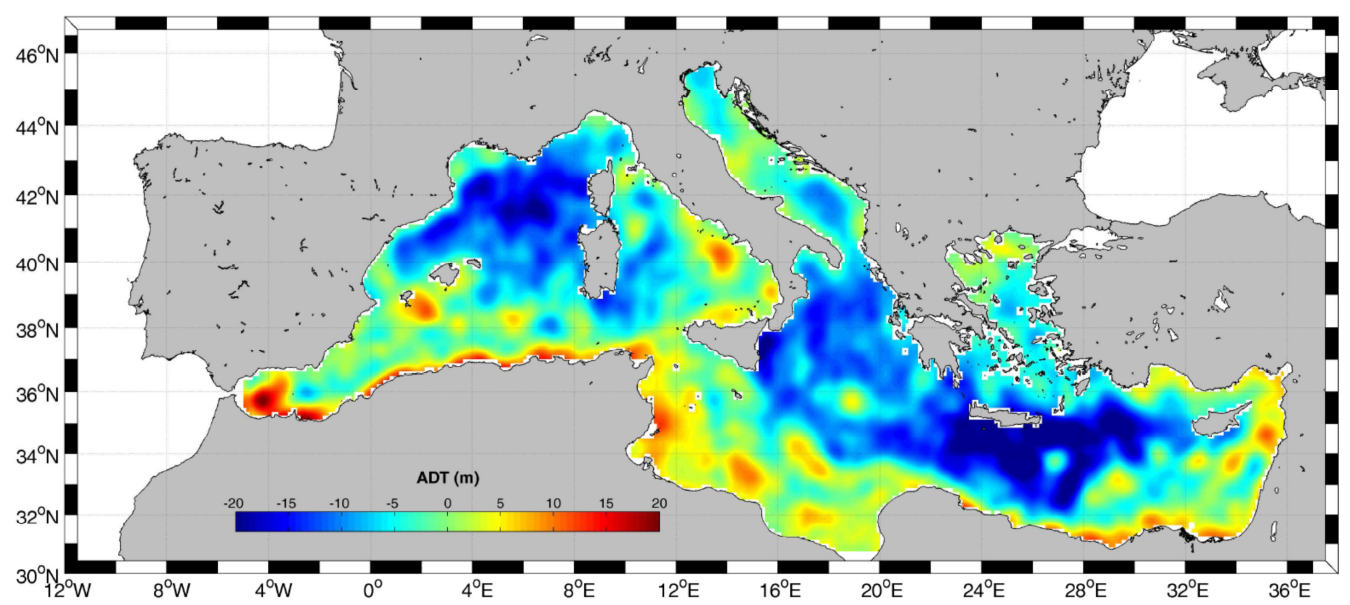

Figure 2c. Monthly absolute dynamic topography (ADT) map of the Mediterranean Sea for April 2011.

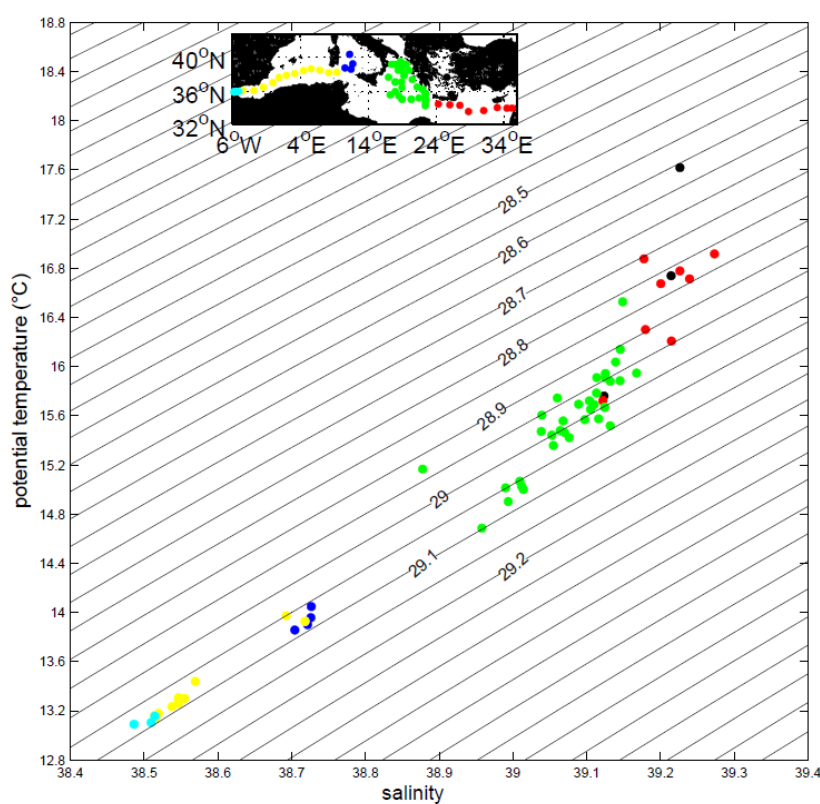

Figure 3. $T-S$ diagram of maximum salinity and corresponding temperature in the layer $50-650 \mathrm{~m}$, which shows the LIW core in the Mediterranean Sea. Colours show different regions. Black dots: Aegean Sea, red dots: Levantine Sea, green dots: Ionian Sea, blue dots: Tyrrhenian Sea, yellow dots: remaining western Mediterranean Sea, cyan dots: Strait of Gibraltar. Isolines for potential density $\sigma_{0}=\rho_{0}$ (referenced to sea surface) $-1000 \mathrm{~kg} \mathrm{~m}^{-3}$ (black continuous line) are given. Inset panel shows the location of the different stations.

CIW can be involved in the salinity maximum. The maximum reaches values of $\sim 39.30\left(\sim 16.80^{\circ}\right.$ for temperature $)$ in the Levantine Sea and reaches values of $\sim 38.50\left(\sim 13.20^{\circ} \mathrm{C}\right.$ for temperature) at the Strait of Gibraltar, after a strong dilution along its way has occurred. Nevertheless, the density differences are small along the whole Mediterranean (from
28.85 to 29.05 increasing westward) due to the compensation between the thermohaline parameters.

During the two cruises the densest water $\left(\sigma_{0}>29.30 \mathrm{~kg} \mathrm{~m}^{-3}, \quad T_{\mathrm{Pot}} \approx 13.95^{\circ} \mathrm{C} \quad\right.$ and $\left.\quad S \approx 39.06\right)$ was found (Fig. 4) in the Aegean Sea (St. 288), and it corresponded to the CDW. However, we did not observe an overflow of such water outside its formation region (see Cardin et al., 2014). The densest water of Adriatic origin $\left(\sigma_{0}<29.27 \mathrm{~kg} \mathrm{~m}^{-3}, T_{\mathrm{Pot}} \approx 13.06^{\circ} \mathrm{C}\right.$ and $S \approx 38.73$, St. 313$)$, instead, was less dense than the CDW, but able to flow out from its formation region through the Strait of Otranto, where $\sigma_{0}$ was still larger than $29.2 \mathrm{~kg} \mathrm{~m}^{-3}, T_{\mathrm{Pot}} \approx 13.28^{\circ} \mathrm{C}$ and $S \approx 38.72$ (St. 352-353).

According to Roether et al. (2007) the anomalously abundant and dense water outflow of Aegean origin produced during the EMT caused a noticeable increase of temperature and salinity throughout the EMed deep waters. Especially in the Levantine basin and in the Hellenic Trench, this increase could be detected as a long-lasting, pronounced $T-S$ inversion (Roether et al., 2013). Indeed, during M84/3 we still can find this inversion in a broad area of the Levantine basin (Fig. 5a). There, $T-S$ values are distributed closely together, with their minima being located at about $1000 \mathrm{~m}$ depth. In the deeper stations (excluding the easternmost three stations) a $T-S$ maximum is reached at about $2200 \mathrm{~m}$ depth, followed by a steady $T$ and $S$ decrease. Those stations located south of the eastern Mediterranean ridge (Fig. 5a, blue, cyan orange, magenta) do not show such strong decreases in temperature and salinity toward the bottom. The $T-S$ distribution is similar, but the minima are found at about $1300-1700 \mathrm{~m}$ depth and the maxima at about $1800-2100 \mathrm{~m}$ depth. The salinity difference between the extreme values is much larger in the Levantine than in the eastern Hellenic Trench. Compared to the distributions found by Roether et al. (2007) during the EMT, the shape of the $T-S$ diagrams changed slightly. During the latter the intermediate maxima were not found in the 


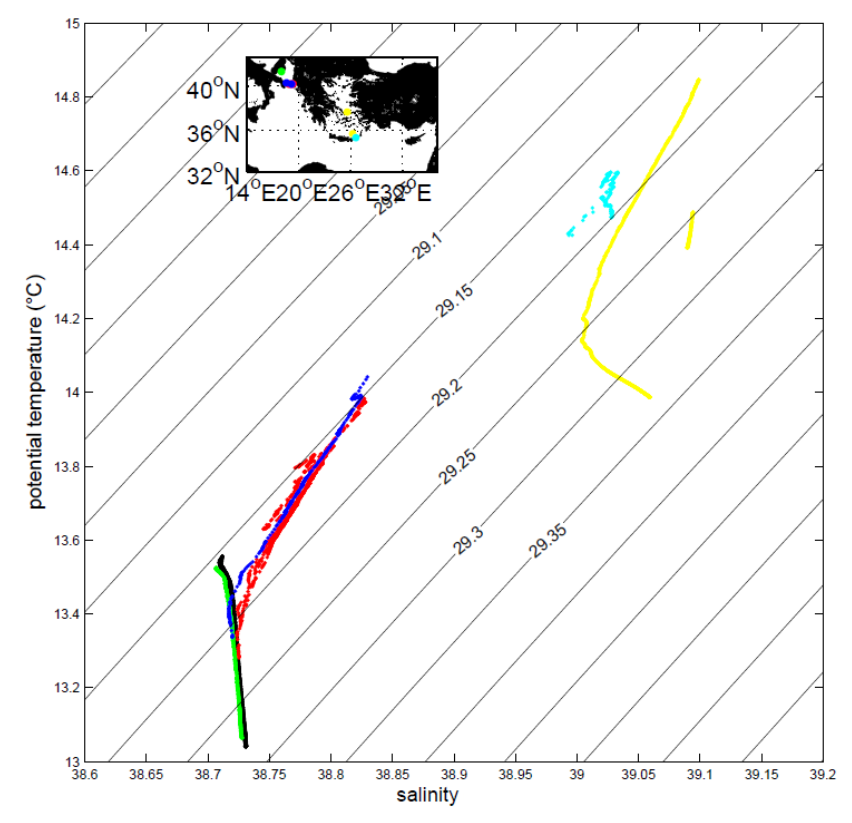

Figure 4. $T-S$ diagram in the areas where dense waters are produced (Aegean and Adriatic Seas). Only values from $600 \mathrm{~m}$ to bottom are considered. Yellow dots: Aegean Sea stations of M84-3. Cyan dots: Kasos Strait station of M84-3. Black dots: Adriatic Pit stations of P414. Green dots: Adriatic Pit stations of M84-3 and red dots: Strait of Otranto, stations of P414. Inset panel shows the location of the different stations.

Levantine basin, but $T$ and $S$ increased steadily in the deep layer, after reaching their minimum. Only in the Hellenic Trench were shapes characterized by intermediate minima and maxima found. Also the depth of the inversions changed. While during the EMT the inversions took place in a layer between $1000-1700 \mathrm{~m}$, this feature can now be found in a wider layer.

During the EMT, this kind of shape of the $T-S$ diagram ("peaking") was prominent in the Ionian Sea only in the northern part of the eastern Mediterranean ridge, the principal entrance for water of Aegean origin (Roether et al., 2007). Remarkably, now it can be found in the whole Ionian Sea (Fig. 5b), but it is characterized by a much less pronounced range between minima and maxima due to presumably ongoing mixing. In general, the $T-S$ range between stations is small. The inversions are also less pronounced in the Ionian Sea than in the Levantine and Hellenic Trench. The depths of the inversions lay between 1200 and $1900 \mathrm{~m}$, the corresponding density level being $\sigma 0=29.18 \mathrm{~kg} \mathrm{~m}^{-3}$ $\left(\sigma 2=37.88 \mathrm{~kg} \mathrm{~m}^{-3}\right)$, which corresponds to the same density level encountered in the Levantine basin. For the deep stations an additional near-bottom minimum can be found at about $3000 \mathrm{~m}$ depth. Salinity is 38.73 in P414, and 38.72 in $\mathrm{M} 84 / 3$ (station 306). Note that salinity increases close to the bottom, while temperature remains constant at $13.42^{\circ} \mathrm{C}$. This minimum corresponds to a branch of old EMDW of Adriatic origin (Bensi et al., 2013a). The increase of salinity further down to the bottom is certainly due to AdDW of very recent origin and leads to the highest density ever observed in the Ionian Sea (Roether et al., 2013).

The stations in the western Hellenic Trench show a more scattered distribution (Fig. 5c). It seems that, especially the P414 stations 362 (black) and 361 (red) and the M84-3 station 300 (cyan) are under the influence of the Antikythera outflow in the upper layers. We note an increase in salinity from April 2011 (M84/3) to June 2011 (P414), which confirms the more direct response of this region to the outflow. In the deepest station (blue) we find a minimum in $T$ and $S$ close to the bottom which is certainly due to advection from the Ionian Sea (Roether et al., 2007).

Since 2005 the deep waters of the WMed experienced significant physical changes (Schroeder et al., 2006; Font et al., 2009). Probably, the major change corresponds to an abrupt increase in the deep heat and salt content. This increase appears as a "hook" in the deep $T-S$ diagrams which arises from the interaction between old deep water, new deep water formed by open-sea convection and dense shelf cascading water (Salat et al., 2009). The data collected during the M84/3 cruise clearly show the presence of this hook-like pattern (Fig. $6 \mathrm{~b}$ and c). In these data, the minimum is located at a depth of about $1200-1600 \mathrm{~m}$, with temperature values of about $12.87-12.89^{\circ} \mathrm{C}$ and salinity values of about 38.4638.48. The differences between the minimum values and the values at the bottom are small: in $T$ and $S<=0.01^{\circ} \mathrm{C}$, psu respectively. The new WMDW is still missing in the Tyrrhenian Sea (Fig. 6a), because of the sill at $1900 \mathrm{~m}$ that separates this sub-basin from the rest of the WMed. Here, the $T-S$ diagrams show an almost linear decrease from mid-depths to the bottom. Bottom values are higher $\left(T \sim 13{ }^{\circ} \mathrm{C}, S \sim 38.5\right)$ than in the "hook" shape case even when depths of more than $1600 \mathrm{~m}$ are reached.

\subsection{Determination of water mass fractions by OMP}

Due to the availability of just three parameters $(T, S, \mathrm{O} 2)$ and to the fact that dissolved oxygen has a very small weight we had to make several separate OMP runs for the western Mediterranean to calculate the fractions of the four relevant water masses. In particular we determined the relation between AW-LIW-WMDWnew, AW-LIW-WMDWold and LIW-WMDWnew-WMDWold.

In all considered OMP cases (Fig. 7a) AW is encountered as a shallow near-surface lens throughout the whole section. Also the appearance of LIW in the intermediate water column from about 200 to $1000 \mathrm{~m}$ with a distinct core at about $500 \mathrm{~m}$ in the eastern side of the section (Fig. 7b) can be observed in all OMP cases. All different OMP combinations also reveal WMDW more or less exclusively in the layers beneath $1000 \mathrm{~m}$, with WMDWnew dominating the deeper layers. Only the combination LIW-WMDWnew-WMDWold could resolve the new WMDW from its old version. 

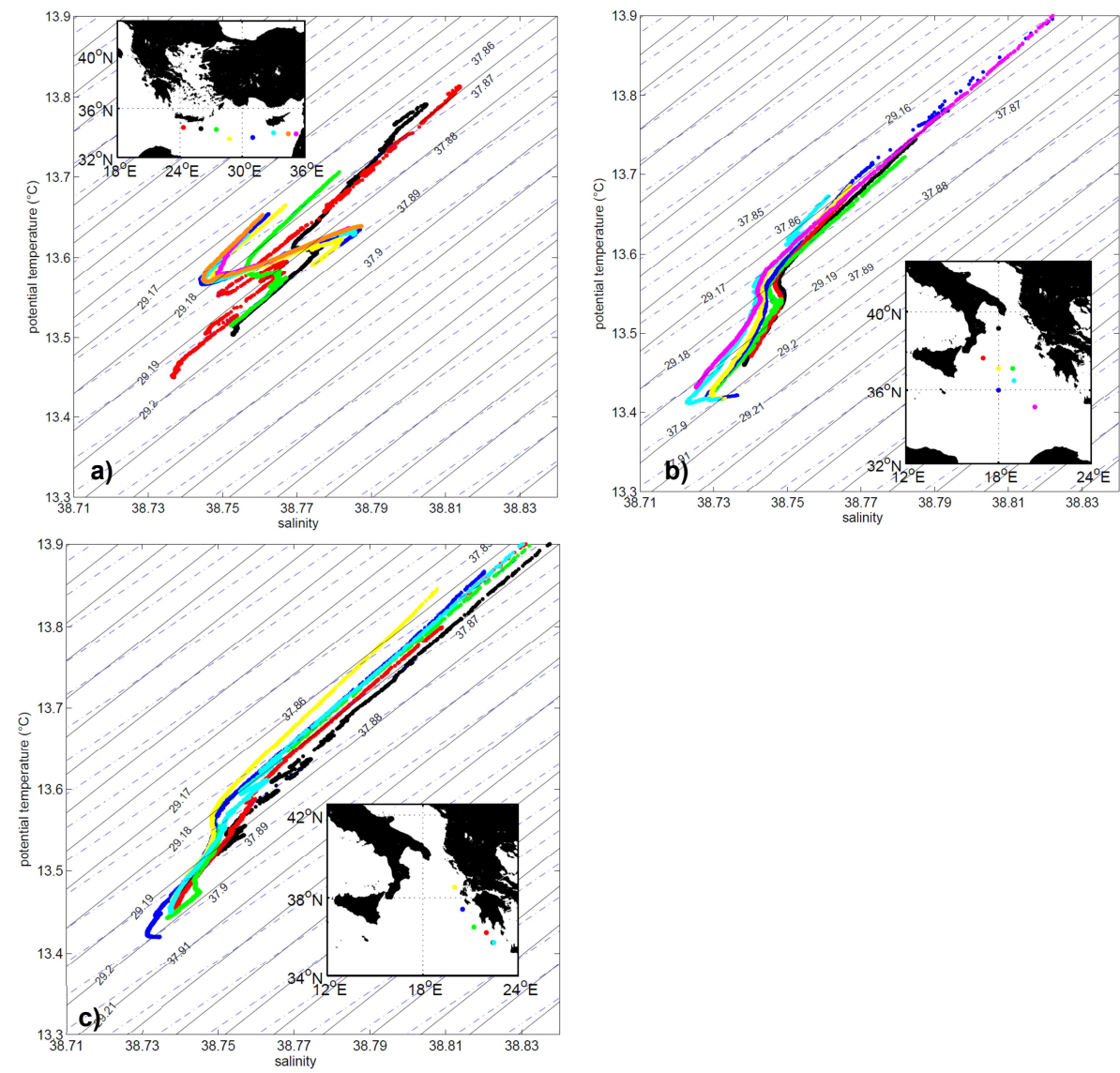

Figure 5. $T-S$ diagrams of M84-3 and P414 CTD stations in (a) the Levantine basin along the eastern Hellenic Trench and south of the eastern Mediterranean ridge, (b) in the Ionian basin (for clarity only selected CTD stations are shown) and (c) in the western part of the Hellenic Trench. Values from $800 \mathrm{~m}$ depth down to the bottom are taken into account. The inset panels show the location of the different stations.

In the case of the EMed we also considered three parameters for our OMP analyses. Again, to compensate for this limitation we carried out different runs to determine the relative importance of the water masses. One run was focused on the upper $500 \mathrm{~m}$ of the water column. Here we combined AW with LSW and LIW. All other runs considered the water column from $500 \mathrm{~m}$ to the bottom. We combined LIW with AdDW and CDW, AW with LIW and AdDW. LSW is dominant in the eastern and central part of the section in the upper $200 \mathrm{~m}$ (Fig. 8a) while LIW is predominant in the intermediate layers throughout the section forming different cores at depths between 100 and $300 \mathrm{~m}$ (Fig. 8b). The different OMP runs for the deep water masses AdDW and CDW produce qualitatively more or less the same results. AdDW fills the basins from $1000 \mathrm{~m}$ to the bottom (Fig. 8d), but with decreasing percentages towards the east where CDW contributes to about $30 \%$ of the deep water (Fig. 8c).

Summarizing our results, we can conclude that, for the EMed, the hydrographic situation which we found in the upper depths during the two cruises reveals well known situation with LSW at the surface and LIW in the intermediate layers. The situation beneath is dominated by water masses originating from the Adriatic Sea, which confirms the assumption that after the EMT, and in particular after 2003, AdDW returned to be the main water mass for deep water formation in the EMed (Hainbucher et al., 2006; Rubino and Hainbucher, 2007; Bensi et al., 2013a). The high amount of AdDW which we found even in the Levantine basin in 2011 together with the fact that the turnover times in the EMed are longer than decades queries the overall importance of AdDW for the deep water formation in the EMed over longer timescales. This is supported by a recent study by Roether et al. (2013) that found no evidence of EMT-like events during the observational record.

\subsection{Geostrophic and mean ADCP velocities}

There are remarkable differences between the geostrophic velocities of the WMed and EMed. Peak velocities (maximum and minimum) are distinctly higher in the WMed than in the EMed, but the structures do not reach as deep and are not as wide as in the EMed. In the former (Fig. 9a) 

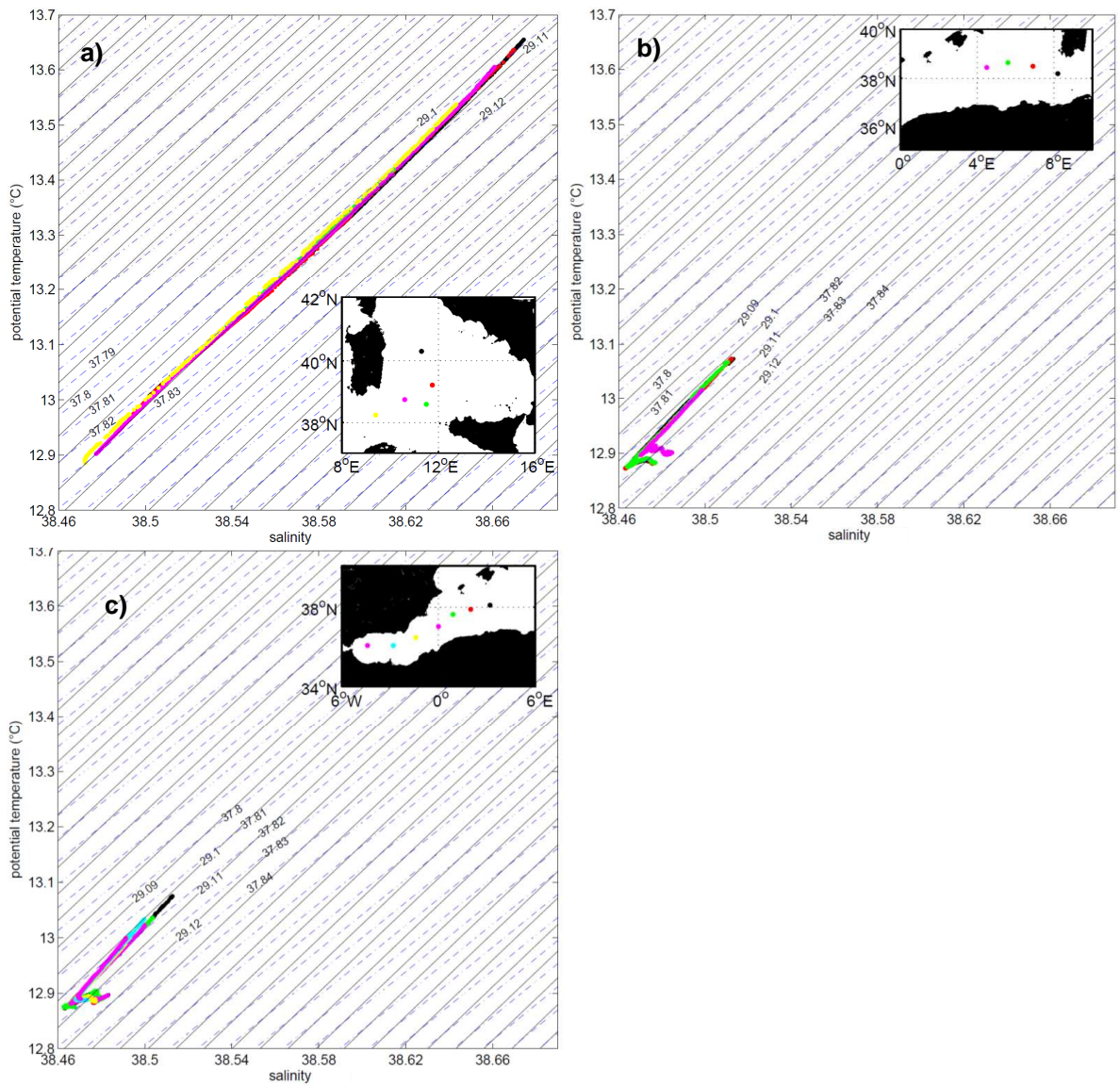

Figure 6. $T-S$ diagrams of M84/3 stations in (a) the Tyrrhenian Sea, (b) the western Mediterranean Sea between the Balearic Islands and Sardinia and (c) the western Mediterranean Sea between Gibraltar and the Balearic Islands. Values from $800 \mathrm{~m}$ depth down to the bottom are taken into account. The inset panels show the location of the different stations.

the features reach down to about $200 \mathrm{~m}$ depth, are of the order of $100 \mathrm{~km}$ width, and reach maximum amplitudes of $12-15 \mathrm{~cm} \mathrm{~s}^{-1}$. Differently, maximum velocities in the EMed are $5 \mathrm{~cm} \mathrm{~s}^{-1}$ and the features widths are about $300-400 \mathrm{~km}$ (Fig. 10a). These structures might be related to sub-basinscale gyres, this assumption being supported by the range of the features and the changing appearance of positive and negative amplitudes. In the EMed the velocity feature is correlated with the Mersa-Matruh anticyclone (Tanhua et al., 2013b, this issue Fig. 2).

In order to compare the ADCP velocities with the results of the geostrophic calculations, the ADCP data collected between two consecutive CTD stations were averaged. The along-track velocities were determined and the velocities across the sections are presented in Figs. $9 \mathrm{~b}$ and 10b. In the EMed, due to data gaps and also to the fact that often the track between CTD stations was not direct, only seven significant CTD stations could be taken into account for applying the method.

Altogether, large velocity amplitudes are achieved mainly in the upper $500 \mathrm{~m}$ of the water column in both basins.
Beneath this water depth current speeds are around 1$2 \mathrm{~cm} \mathrm{~s}^{-1}$. For the WMed, geostrophic velocities and mean ADCP velocities agree well. Structures and amplitudes are similar and the ageostrophic fraction (Fig. 9c) determined by subtracting the geostrophic velocity from the ADCP velocity is comparably low. Based on this result, we conjecture that during the measurements large-scale velocities in the upper part of the ocean were mainly determined by geostrophy in the WMed, while in the EMed the situation was opposite. Again, the largest velocities were reached in the area of the Mersa-Matruh anticyclonic gyre. These far exceed the calculated geostrophic velocity with maximum amplitudes of more than $12 \mathrm{~cm} \mathrm{~s}^{-1}$ (Fig. 10c), indicating that the ageostrophic fraction in the EMed circulation areas exerted a larger role in shaping the observed velocity distribution.

\section{Summary and conclusion}

In the EMed the effects induced by the EMT on the deep layers (increase in temperature and salinity due to the massive production of $\mathrm{CDW}$ ) were still visible during our cruises 


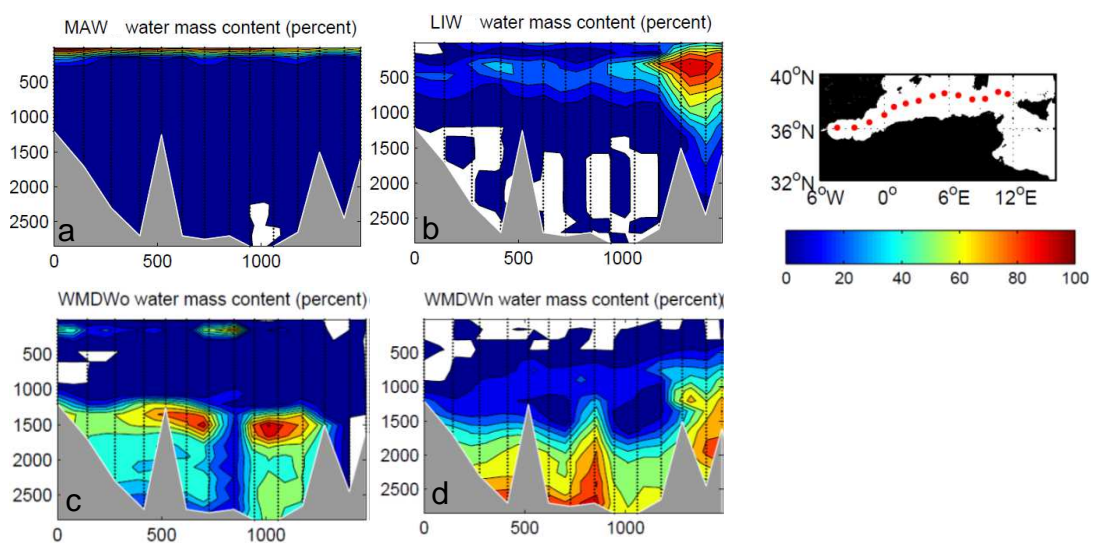

Figure 7. Water mass fractions in percent for the western Mediterranean Sea. Panels (a, b) show Modified Atlantic Water and Levantine

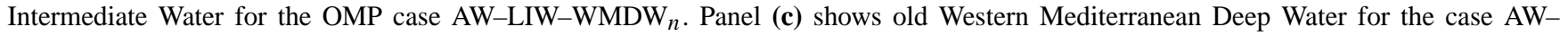
$\mathrm{WMDW}_{n}-\mathrm{WMDW}_{o}$ and panel (d) shows new Western Mediterranean Deep Water for the case LIW-WMDW $-\mathrm{WMDW}_{o}$. The $y$ axes indicate depth in dbar and $x$ axes specify distance in $\mathrm{km}$. The right panel shows the location of considered stations. White patches are areas for which the OMP method is not valid.

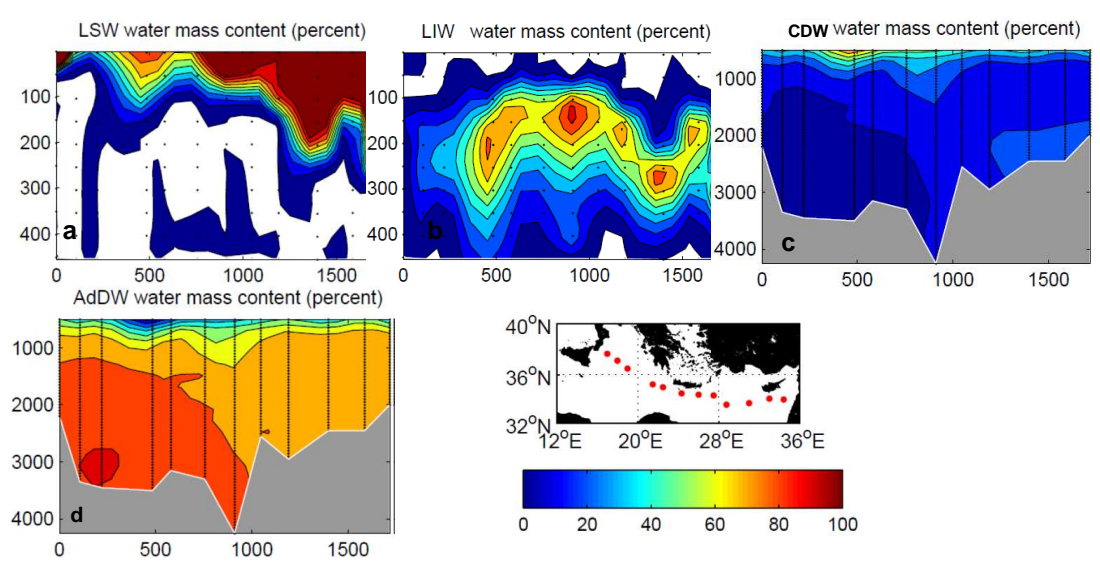

Figure 8. Water mass fractions in percent for the eastern Mediterranean Sea. (a) Levantine Surface Water from surface to $500 \mathrm{~m}$. (b) Levantine Intermediate Water from surface to $500 \mathrm{~m}$. Panels $(\mathbf{a}, \mathbf{b})$ result from the OMP run which combines AW, LSW and LIW in the upper $500 \mathrm{~m}$. (c) Cretan Deep Water from $500 \mathrm{~m}$ to bottom. (d) Adriatic Deep Water from $500 \mathrm{~m}$ to bottom. Panels (c, d) result from an OMP combination of AW, AdDW and CDW from $500 \mathrm{~m}$ down to the bottom. Lower right panel: location of section and colour scale for percentage. Left axis of panels: depth in dbar; lower axis: distance in $\mathrm{km}$. White patches are areas for which the OMP method is not valid.

(2011). $T-S$ diagrams show that the AdDW returned to represent the main source for the EMDW. However, it became much saltier and warmer than before the EMT. Our analyses show that this water mass represents also the dominating water filling the deeper basins of the EMed, in the Levantine also CDW added during the peak years of the EMT is still present (Roether et al., 2013). CDW of more recent outflows is limited to a shallower layer (approximately around $2000 \mathrm{~m}$ ) in the proximity of Kasos Strait. In the upper layer of the EMed, LIW is prevailing in the intermediate layers, while AW dominates in the western part of the EMed and LSW in the eastern regions. The velocity distribution derived by the ADCP measurements and geostrophic calculations indicates that in the EMed the ageostrophic component of the velocity is stronger than in the WMed. Large velocity amplitudes $\left(>10 \mathrm{~cm} \mathrm{~s}^{-1}\right.$ ) can only be found in the upper $500 \mathrm{~m}$ of the water column.

In the WMed the stratification in the deep layers is dominated by the "hook" shape of the $T-S$ distribution, indicating a transition in bottom waters between old and new WMDW. One exception is represented by the stratification found in the Tyrrhenian Sea, where temperature and salinity did not reach the range where the "hook" typically occurs. Here, temperature and salinity are distinctly higher than further west and are influenced by strong downward mixing of Sicily Strait overflow (Gasparini et al., 2005; Roether and Lupton, 2011). In the deep layers of the rest of the WMed, WMDW is filling the basin, but from our results we cannot discern whether new or old WMDW dominates. In the upper layers, AW is predominant in the surface layers, whereas LIW is filling 

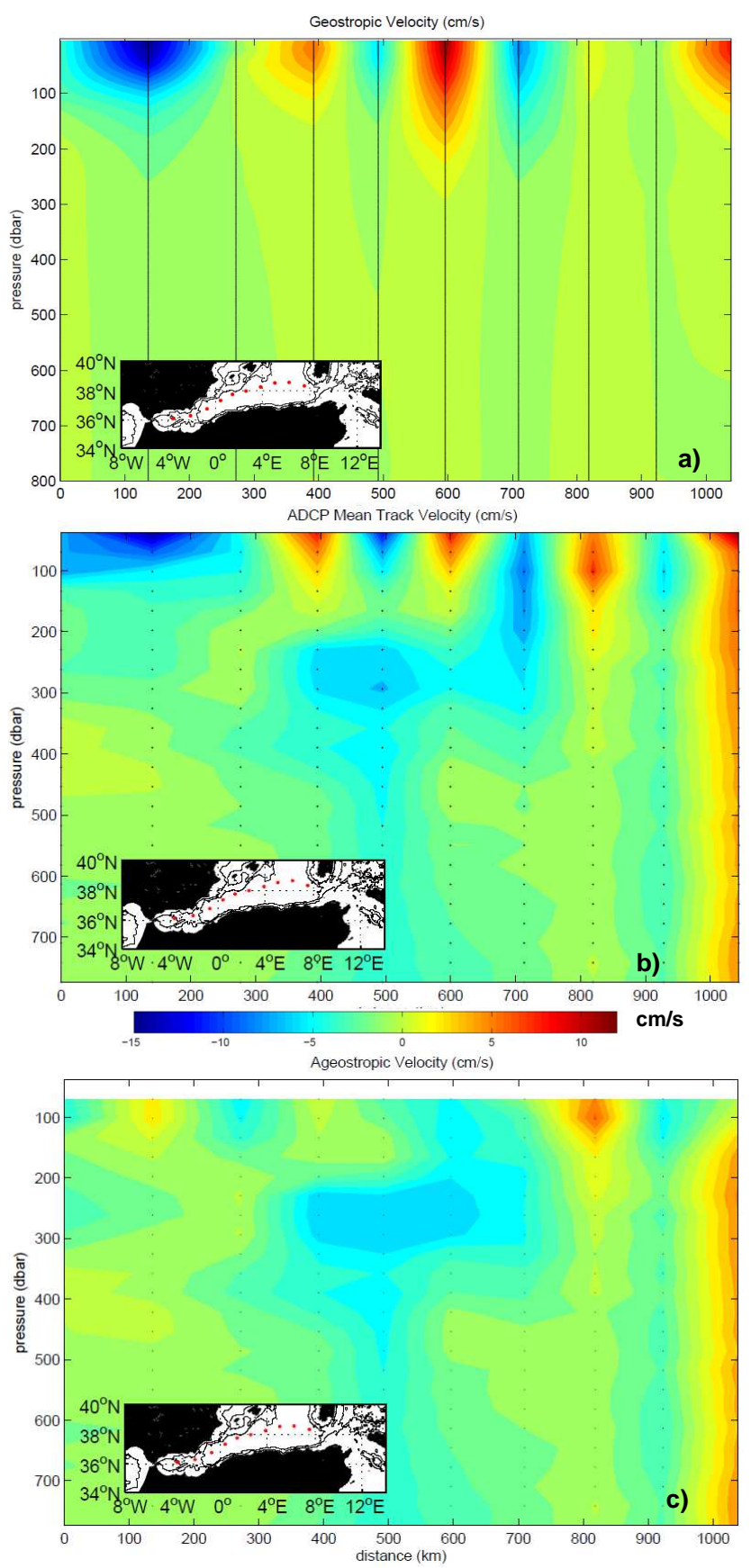

Figure 9. Velocity distribution on a section through the western Mediterranean Sea. The inset panels show the location and nodes of the section. Left axis of panels: depth in dbar; lower axis: distance in $\mathrm{km}$. (a) Geostrophic velocity determined between the CTD stations. (b) Mean ADCP velocity across the section between adjoining CTD stations. Means are calculated between two CTD stations. (c) Ageostrophic velocity determined by subtracting the geostrophic velocity from the mean ADCP velocity. Reference layer of no motion for geostrophic velocities is $1000 \mathrm{~m}$.
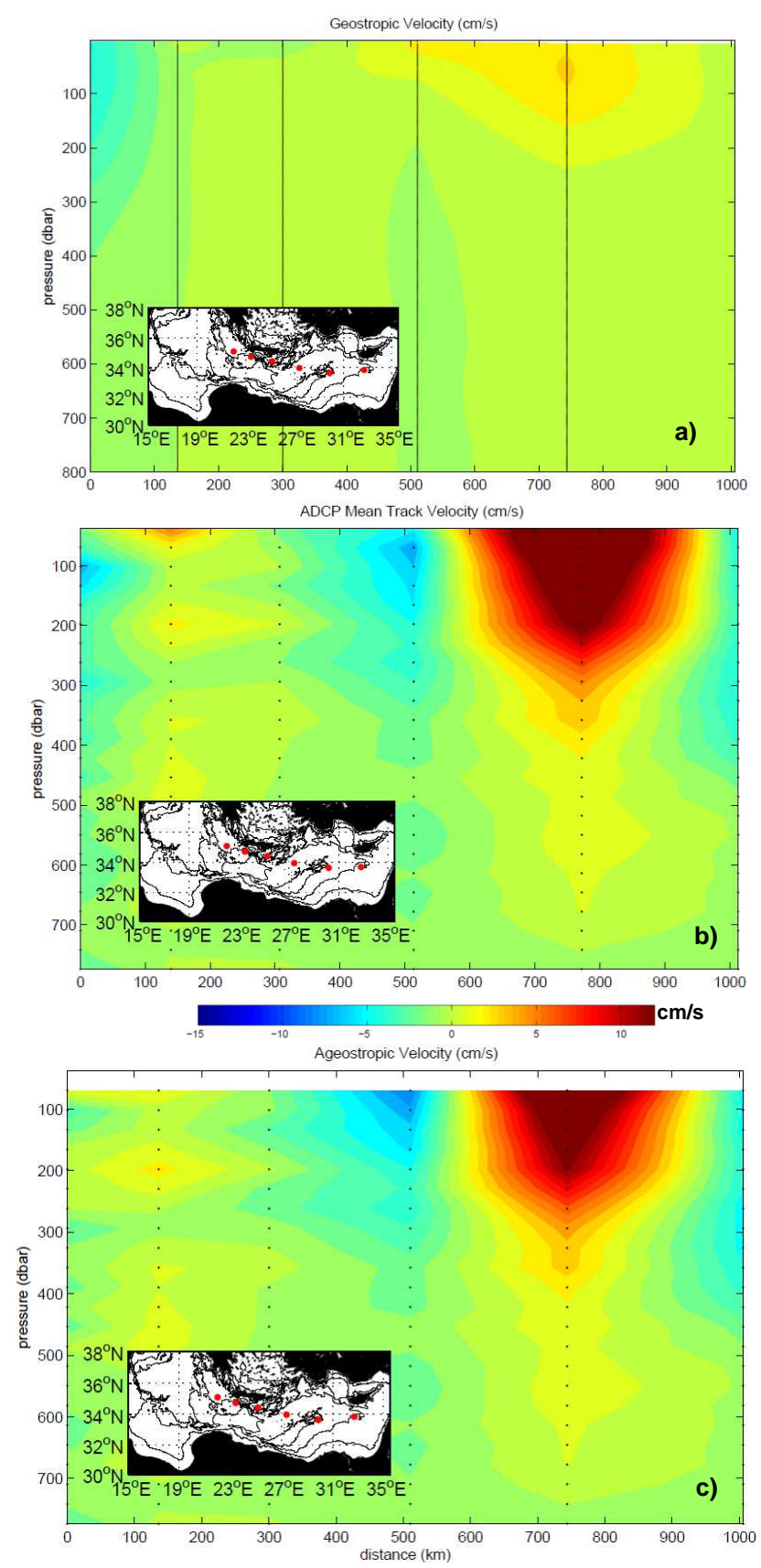

Figure 10. Velocity distribution on a section through the eastern Mediterranean Sea. The inset panels show the location and nodes of the section. Left axis of panels: depth in dbar; lower axis: distance in $\mathrm{km}$. (a) Geostrophic velocity determined between the CTD stations. (b) Mean ADCP velocity across the section between adjoining CTD stations. Mean is the average between two CTD stations. (c) Ageostrophic velocity determined by subtracting the geostrophic velocity from the mean ADCP velocity. Reference layer of no motion for geostrophic velocities is $1000 \mathrm{~m}$. 
the intermediate depth levels with a core in the eastern part of the WMed. In contrast to the EMed, the velocity here is more geostrophically balanced. In both basins the observed structures are related to sub-basin-scale gyres - in the EMed we even can correlate the velocity feature we found with the Mersa-Matruh anticyclone.

The salinity range in the WMed is larger than in the EMed, certainly due to input of fresher water of Atlantic origin. On the other hand, the temperature range in both regions is of the same order. Bottom densities of the WMed are lower than in the EMed and are determined by lower salinity. In contrast, LIW is lighter in the EMed and the mean depth at which LIW flows deepens from east to west.

Overall, we can conclude that the hydrographic property distribution which we found during April-June 2011 in the western and eastern Mediterranean Sea characterizes a situation which is far from that observed before the EMT. The picture which emerges adds further information toward a deeper understanding of long-term evolution of hydrography and large-scale circulation of the Mediterranean Sea.

Acknowledgements. The authors want to thank the captains and crews on the research vessels RV Meteor and RV Poseidon for the excellent cooperation during the campaigns. Thanks go to all scientists involved in the field campaigns. Special thanks go to Norbert Verch for processing and calibrating the hydrographic data of both cruises.

The Meteor cruise M84/3 was supported by a grant from the Deutsche Forschungsgemenschaft - Senatskommission für Ozeanographie (DFG), and from a grant from the DFG; TA 317/3-1. The Poseidon cruise 414 was supported by funding from the University of Hamburg.

Edited by: N. Kress

\section{References}

Bensi, M., Rubino, A., Cardin, V., Hainbucher, D., and ManceroMosquera, I.: Structure and variability of the abyssal water masses in the Ionian Sea in the period 2003-2010, J. Geophys. Res., 118, 1-13, doi:10.1029/2012JC008178, 2013a.

Bensi, M., Cardin, V., Rubino, A., Notarstefano, G., and Poulain, P. M.: Effects of winter convection on the deep layer of the Southern Adriatic Sea in 2012, J. Geophys. Res.-Ocean, 118, 60646075, doi:10.1002/2013JC009432, 2013 b.

Bethoux, J. P., Gentili, B., Raunet, J., and Taillez, D.: Warming trend in the Western Mediterranean deep water, Nature, 347, 660-662, 1990.

Borzelli, G. L. E., Gačic, M., Cardin, V., and Civitarese, G.: Eastern Mediterranean Transient and reversal of the Ionian Sea circulation, Geophys. Res. Lett., 36, L15108, doi:10.1029/2009GL039261, 2009.

Cardin, V., Bensi, M., and Pacciaroni, M.: Variability of water mass properties in the last two decades in the South Adriatic Sea with emphasis on the period 2006-2009, Cont. Shelf Res., 31, 951965, 2011.
Cardin, V., Civitarese, G., Hainbucher, D., Bensi, M., and Rubino, A.: Thermohaline properties in the Eastern Mediterranean in the last three decades: is the basin returning to the pre-EMT situation?, Ocean Sci. Discuss., 11, 391-423, doi:10.5194/osd-11391-2014, 2014.

Font, J., Béranger, K., Bryden, H., Budillon, G., Fuda, J. L., Gaèiæ, M., Gascard, J. C., Packard, T., Puig, P., Roether, W., Salat, J., Salusti, E., Schroeer, K., Theocharis, A., and van Haren, H.: Executive summary of CIESM workshop 38 "Dynamics of Mediterranean deep waters", in: CIESM, 2009, Dynamics of Mediterranean Deep Waters, N_38 in CIESM Workshop Monographs, edited by: Briand, F., Monaco, 132 pp., 2009.

Gačic, M., Borzelli, G. L. E., Civitarese, G., Cardin, V., and Yari, S.: Can internal processes sustain reversals of the ocean upper circulation? The Ionian Sea example, Geophys. Res. Lett., 37, L09608, doi:10.1029/2010GL043216, 2010.

Gasparini, G. P., Ortona, A., Budillon, G., Astraldi, M., and Sansone, E.: The effect of the Eastern Mediterranean Transient on the hydrographic characteristics in the Strait of Sicily and in the Tyrrhenian Sea, Deep Sea Res. Pt. I, 52, 915-936, 2005.

Gertman, I., Pinardi, N., Popov, Y., and Hecht, A.: Aegean Sea water masses during the early stages of the Eastern Mediterranean Climatic Transient (1988-1990), J. Phys. Oceanogr., 36, 18411859, 2006.

Hainbucher, D.: Cruise Report RV POSEIDON Cruise P414, available at: http://www.geomar.de/fileadmin/content/zentrum/ ze/fs/Poseidon_Berichte_2011_PDF/POS414_Hainbucher.pdf (last access: 12 December 2013), 2012.

Hainbucher, D., Rubino, A., and Klein, B.: Water mass characteristics in the deep layers of the western Ionian Basin observed during May 2003, Geophys. Res. Lett., 33, L05608, doi:10.1029/2005GL025318, 2006.

Klein, B., Roether, W., Manca, B. B., Bregant, D., Beitzel, V., Kovacevic, V., and Luchetta, A.: The large deep water transient in the Eastern Mediterranean, Deep-Sea Res. Pt. I, 46, 371-414, 1999.

Kovačević, V., Manca, B. B., Ursella, L., Schroeder, K., Cozzi, S., Burca, M., Mauri, E., Gerin, R., Notarstefano, G., and Deponte, D.: Water mass properties and dynamic conditions of the Eastern Mediterranean in June 2007, Prog. Oceanogr., 104, 59-79, 2012.

Lascaratos, A.: Estimation of deep and intermediate water mass formation rates in the Mediterranean Sea, Deep-Sea Res. Pt. II, 40, 1327-1332, 1993.

Lascaratos, A., Roether, W., Nittis, K., and Klein, B.: Recent changes in deep water formation and spreading in the Eastern Mediterranean Sea: a review, Progr. Oceanogr., 44, 5-36, 1999.

Leaman, K. D. and Schott, F.: Hydrographic structure of the convection regime in the Golfe du Lion, J. Phys. Oceanogr., 23, 575598, 1991.

López-Jurado, J.-L., González-Pola, C., and Vélez-Belchi, P.: Observation of an abrupt disruption of the long-term warming trend at the Balearic Sea, western Mediterranean Sea, in summer 2005, Geophys. Res. Lett., 32, L24606, doi:10.1029/2005GL024430, 2005.

Malanotte-Rizzoli, P. and Hecht, A.: Large-scale properties of the eastern Mediterranean: a review, Oceanol. Acta, 11, 323-335, 1988.

Malanotte-Rizzoli, P., Manca, B. B., Ribera d'Alcala, M., Teocharis, A., Bergamasco, A., Bregant, D., Budillon, G., Civ- 
itarese, G., Georgopoulos, D., Michelato, A., Sansone, E., Scarazzato, P., and Souvermezoglou, E.: A synthesis of the Ionian Sea hydrography, circulation and water mass pathways during POEM-Phase I, Prog. Oceanogr., 39, 153-204, 1997.

Malanotte-Rizzoli, P., Manca, B. B., Ribera d'Alcala, M., Theocharis, A., Brenner, A., Budillon, G., and Ozsoy, E.: The Eastern Mediterranean in the $80 \mathrm{~s}$ and in the 90s: the big transition in the intermediate and deep circulations, Dynam. Atmos. Oceans, 29, 365-395, 1999.

Millot, C.: Circulation in the Western Mediterranean Sea, J. Marine Syst., 20, 423-444, 1999.

Moutin, T., Van Wambeke, F., and Prieur, L.: Introduction to the Biogeochemistry from the Oligotrophic to the Ultraoligotrophic Mediterranean (BOUM) experiment, Biogeosciences, 9, 38173825, doi:10.5194/bg-9-3817-2012, 2012.

Molcard, A., Gervasio, L., Griffa, A., Gasparini, G. P., Mortier, L., and Özgökmen, T. M.: Numerical investigation of the Sicily Channel dynamics: density currents and water mass advection, J. Marine Syst., 36, 219-238, 2002.

Ovchinnikov, I. M.: Intermediate Water formation in the Mediterranean Sea, Okeanologiya, 24, 217-225, 1984.

Özturgut, E.: The Source and Spreading of the Levantine Intermediate Water in the Eastern Mediteranean, Saclant ASW Research Center Memorandum Sm-92, La Spezia, Italy, 45 pp. 1976.

POEM Group: General circulation of the eastern Mediterranean, Earth-Sci. Rev., 32, 285-309, 1992.

Pierini, S. and Rubino, A.: Modeling the oceanic circulation in the area of the Strait of Sicily: the remotely forced dynamics, J. Phys. Oceanogr., 31, 1397-1412, 2001.

Robinson, A. R., Leslie, W. G., Theocharis, A., and Lascaratos, A.: Mediterranean Sea Circulation Encyclopedia of Ocean Sciences, Academic Press, 1689-1706, 2001.

Roether, W. and Lupton, J. E.: Tracers confirm downward mixing of Tyrrhenian Sea upper waters associated with the Eastern Mediterranean Transient, Ocean Sci., 7, 91-99, doi:10.5194/os7-91-2011, 2011.

Roether, W., Manca, B. B., Klein, B., Bregant, D., Georgopoulos, D., Beitzel, V., Kovacevic, V., and Lucchetta, A.: Recent changes in Eastern Mediterranean deep waters, Science, 271, 333-335, 1996.

Roether, W., Klein, B., Beitzel, V., and Manca, B. B.: Property distributions and transient-tracer ages in Levantine Intermediate water in the Eastern Mediterranean, J. Marine Syst., 18, 71-87, 1998.

Roether, W., Klein, B., Manca, B. B., Theocharis, A., and Kioroglou, S.: Transient Eastern Mediterranean deep waters in response to the massive dense-water output of the Aegean Sea in the 1990s, Prog. Oceanogr., 74, 540-571, 2007.

Roether, W., Klein, B., and Hainbucher, D.: The Eastern Mediterranean transient: evidence for similar events previously?, in: The Mediterranean Sea: Temporal Variability and Spatial Patterns, edited by: Borzelli, G. L. E., AGU monographs, 2013.
Rubino, A. and Hainbucher, D.: A large abrupt change in the abyssal water masses of the eastern Mediterranean, Geophys. Res. Lett., 34, L23607, doi:10.1029/2007GL031737, 2007.

Salat, J., Emelianov, M., and Puig, P.: From bottom water (Lacombe, 1985) to New-WMDW since 2005, Possible shifts on open sea deep convection, in: CIESM, 2009, Dynamics of Mediterranean Deep Waters, N_38 in CIESM Workshop Monographs, edited by: Briand, F., Monaco, 132 pp., 2009.

Schlitzer, R., Roether, W., Oster, H., Junghans, H.-G., Hausmann, M., and Michelato, A.: Chlorofluoromethane and oxygen in the eastern Mediterrancah, Deep-Sea Res., 38, 1531-1551, 1991.

Schneider, A., Tanhua, T., Roether, W., and Steinfeldt, R.: Changes in ventilation of the Mediterranean Sea during the past 25 year, Ocean Sci., 10, 1-16, doi:10.5194/os-10-1-2014, 2014.

Schroeder, K., Gasparini, G. P., Tangherlini, M., and Astraldi, M.: Deep and intermediate water in the Western Mediterranean under the influence of the Eastern Mediterranean Transient, Geophys. Res. Lett., 33, L21607, doi:10.1029/2006GL027121, 2006.

Schroeder, K., Ribotti, A., Borghini, M., Sorgente, R., Perilli, A., and Gasparini, G. P.: An extensive western Mediterranean deep water renewal between 2004 and 2006, Geophys. Res. Lett., 35, LI8605, doi:10.1029/2008GL035146, 2008.

Schroeder, K., Schroeder, K., Garcìa-Lafuente, J., Josey, S. A., Artale, V., Buongiorno Nardelli, B., Carrillo, A., Gacic, M., Gasparini, G. P., Herrmann, M., Lionello, P., Ludwig, W., Millot, C., Özsoy, E., Pisacane, G., Sánchez-Garrido, J. C., Sannino, G., Santoleri, R., Somot, S., Struglia, M., Stanev, E., Taupier-Letage, I., Tsimplis, M. N., Vargas-Yáñez, M., Zervakis, V., and Zodiatis, G.: Circulation of the Mediterranean Sea and its variability, in: The Climate of the Mediterranean Region: From the Past to the Future, edited by: Lionello, P., Elsevier Insights, Amsterdam, 2012.

Tanhua, T., Hainbucher, D., Cardin, V., Álvarez, M., Civitarese, G., McNichol, A. P., and Key, R. M.: Repeat hydrography in the Mediterranean Sea, data from the Meteor cruise 84/3 in 2011, Earth Syst. Sci. Data, 5, 289-294, doi:10.5194/essd-5-289-2013, 2013a.

Tanhua, T., Hainbucher, D., Schroeder, K., Cardin, V., Álvarez, M., and Civitarese, G.: The Mediterranean Sea system: a review and an introduction to the special issue, Ocean Sci., 9, 789-803, doi:10.5194/os-9-789-2013, 2013b.

Theocharis, A., Nittis, K., Kontoyiannis, H., Papageorgiou, E., and Balopoulos, E.: Climatic changes in the Aegean Sea influence the Eastern Mediterranean thermohaline circulation (1986-1997), Geophys. Res. Lett., 26, 1617-1620, 1999.

Tomczak, M.: A multiparameter extension of temperature/salinity diagram techniques for the analysis of non-isopycnal mixing, Prog. Oceanogr., 10, 147-171, 1981.

Tomczak, M. and Large, D. G. B.: Optimum multiparameter analysis of mixing in the thermocline of the Eastern Indian Ocean, J. Geophys. Res., 94, 16141-16149, 1989. 